Book Review

\title{
Our Sports Clubs: The Sport-for-All Dream in Crisis? Book Review of Our Kids: The American Dream in Crisis. By Robert Putnam. New York: Simon \& Schuster, 2015, 400 pp.; ISBN: 1476769893.
}

\author{
Reinhard Haudenhuyse \\ Sport \& Society Research Unit, Vrije Universiteit Brussel, 1050 Brussels, Belgium; E-Mail: reinhard.haudenhuyse@vub.ac.be
}

Submitted: 22 December 2017 | Published: 29 June 2017

\begin{abstract}
This review investigates the potential implications of Putnam's recent book Our Kids: The American Dream in Crisis for the field of social sport sciences. The main themes in Putnam's Our Kids are class segregation and the widening 'opportunity' gap between the 'have' and 'have nots' in American society. The question can and needs to be asked: what the impact of class-based segregation has been on 'our sport clubs'? Furthermore, Putnam also discusses the importance and unequal provision of Extracurricular activities. Putnam sees such activities as contexts for developing social skills, a sense of civic engagement and even for generating upward mobility. An important advantage of such activities is, according to Putnam, the exposure to caring adults outside the family, who can often serve as valuable mentors. However, throughout the book, Putnam uses a rather judgmental and moralizing language when talking about the parents of the 'have nots'. The lesson that sport researchers can learn from this is to be sensitive and critical to moralizing approaches and deficiency discourses regarding the inclusion in and through sport of children and youth living in poverty.
\end{abstract}

\section{Keywords}

elite; inequality; social class; sport

Issue

This book review is part of the issue "Sport for Social Inclusion: Questioning Policy, Practice and Research", edited by Reinhard Haudenhuyse (Vrije Universiteit Brussel, Belgium).

(C) 2017 by the author; licensee Cogitatio (Lisbon, Portugal). This article is licensed under a Creative Commons Attribution 4.0 International License (CC BY).

It was as if the poor kids had weights attached to their

feet that grew heavier and heavier with each step up the ladder. (Putnam, 2015, p. 188)

\section{Class Segregation and Scissor Graphs}

Putnam's Bowling Alone: The Collapse and Revival of American Community had an enormous impact on sport academics and policymakers alike. In this article, I review the potential implications of Putnam's latest book Our Kids for the field of social sport sciences.

The main themes in Putnam's Our Kids are class segregation and the widening opportunity gap between the 'have' and 'have nots' in American society. Throughout the book, this gap is visually illustrated by scissor-shaped charts showing how the gap has and is widening in multiple domains in relation to family, parenting, school- ing and community. Putnam's motivation for writing Our Kids is mainly to give voice to the 'have nots'. Putnam puts the life stories of rich and poor families at the center of the book. He uses what can be described as an ethnographic-inspired narrative approach, with the aim of generating life histories. These narratives illustrate the differences in opportunities and constraints of children and their families in relation to growing up. In total, 107 young adults and their parents were interviewed on multiple research sites in the United States. Our Kids also uses online research strategies. For example, Facebook was used in order to keep track of the working class young adults whose lives and housing situations often rapidly changed:

Watching them post and interact on Facebook also gave us deeper information than a single interview 
could, and with their permission we used their updates and posts in our analysis. (Putnam, 2015, p. 269)

The stories in Our Kids vividly illustrate how growing up has changed over the last few decades and how the opportunity gap has widened and deepened along class lines. Putnam argues that 'economically successful' people and their children have less to no idea how the 'other side' lives, with the consequence that such people might be less empathetic to the plight of the less privileged. Precisely because of growing class segregation, writing up such stories is, according to Putnam, necessary as it will help to reduce this gap in perceptions. On a more personal note, Putnam confesses that his assumptions were quite different before he embarked on the research of Our Kids: "If I and my classmates could climb the ladder, I assumed, so could kids from modest backgrounds today. Having finished this research, I know better." (Putnam, 2015, p. 230).

\section{2. 'Our Sport Clubs'}

Putnam writes that the economic gap has been accompanied by growing de facto segregation of Americans along class lines. Putnam describes such class-based residential polarization as a kind of incipient class apartheid:

...class segregation across America has been growing for decades, so fewer affluent kids live in poor neighborhoods, and fewer poor kids live in rich neighborhoods....Does the character of the neighborhood where kids grow up have an effect on their future prospects, apart from their individual characteristics?....The question is whether growing up in a poor neighborhood imposes any additional handicaps. (Putnam, 2015, p. 217)

The question can be asked what the impact of classbased segregation has been on 'our sport clubs'? Can we see the same class-apartheid in our sport clubs? Or is sport, through its assumed leveling playing field, somehow able to withstand such class-based dynamics? And if there is a class-based apartheid, what is the personal and societal impact in relation to young people and their families (both advantaged and disadvantaged) regarding their participating and non-participation in sport (e.g., the impact of non-exposure to people outside one's own socioeconomic class)? This issue needs to be addressed if the social and economic transformation of neighborhoods, as Putnam repeatedly visualized by scissor charts and illustrated by real-life stories, has had a societal footprint on sport clubs. How do sport clubs fare in the face of intensified social class segregation in domains such as education, health, community and work? In relation to schools, Putnam asks if schools in America today are widening or reducing the growing gaps between have and have-not kids, or do they have little impact? The same question can be reiterated for sport clubs: are they widening the gap or are they just 'innocent bystanders'? Such questions need to be addressed, as they have too often remained peripheral amongst sport researchers.

\section{Mentoring}

Involvement in organized, adult-supervised leisure activities has been associated with positive developmental outcomes for youth (e.g., Eccles \& Gootman, 2002; Feinstein, Bynner, \& Duckworth, 2006). Putnam sees such activities as contexts for developing social skills (e.g., work habits, self-discipline, teamwork, leadership), a sense of civic engagement and even for generating upward mobility. Moreover, according to Putnam, an important advantage of such activities is the exposure to caring adults outside the family, such as coaches and other adult supervisors who can often serve as valuable mentors:

Mentoring can make a measurable difference in kids' lives, but we also saw that formal mentoring programs have so far barely begun to close the enormous class gap in access to informal mentoring....To be sure, serious mentoring requires serious training, careful quality control, and above all, stability. Mentoring works best as the by-product of a connection that rests on some shared interest. (Putnam, 2015, p. 259)

Interesting in the above citation is the distinction Putnam makes between formal and informal mentoring. This might be a potentially interesting line for sport researchers. For example: are coaches seen as playing a mentoring role and what are the optimal conditions and underlying processes of successful mentoring relationships in terms of generating positive developmental outcomes? We should, however, be careful in overestimating the feasibility of 'mentoring children out of poverty', as this risks legitimating a reductive analysis of complex processes by highlighting individual deficits of both the parents and children, and de-emphasising structural inequalities (Kelly, 2011).

\section{Unequal Leisure Opportunities and Outcomes}

A substantial class gap seems to be equally present in organized leisure activities. What is more, Putnam illustrates that schools and communities with substantially more less-affluent kids have less ability to provide Extracurricular or organized leisure opportunities, and furthermore lack youth-specific infrastructure and services. Money seems to matter. Putnam (2015, p. 167) formulates that in most cases the growing class gap in parental engagement, such as with their children's organized sport participation, is due less to lack of motivation than to economic and cultural obstacles. In Our Kids, Putnam refers to several high-quality experimental studies showing that giving poor families money can improve the academic and social performance of their children. Similar experimental settings could be set up in which 
communities or families are given money and where outcomes are controlled and measured in terms of organized leisure participation and positive youth developmental outcomes. However, such experimental designs seem overly ambitious (and expensive). Perhaps it would be more feasible to use quasi-experimental research designs to investigate the impact of ending or introducing pay-to-play for extracurricular activities.

\section{Moralizing Discourse}

Throughout the book, and especially in the chapter on parenting, Putnam uses a rather judgmental and moralizing language when talking about the parents of the have nots. Two fragments illustrate this:

..."good parenting" has become time-consuming and expensive.....Parents at all levels of society now aspire to intensive parenting, but, as we shall see, the less educated and less affluent among them have been less able to put those ideals in practice (p. 118)

Family dining is no panacea for child development, but it is one indicator of the subtle but powerful investments that parents make in their kids (or fail to make). (p. 123)

Whereas the narratives in Our Kids might be rich, in the chapter on parenting, the evidence-base is rather thin. Some of Putnam's proposals such as daily reading to children, coaching poor parents through house visits and family dining run the danger of decontextualizing structural causes of poverty. Furthermore, they seem to put the blame on parents for the poverty of their children. Putnam's multiple references regarding brain development research further ignores the critical literature-both in terms of the scientific robustness and generalizability of the evidence-that has been written on the so-called 'hard evidence' of brain development research in relation to poverty (e.g., Edwards, Gillies, \& Horsley, 2015; MacVarish, Lee, \& Lowe, 2015). MacVarish et al. (2015), for example, argue that targeting families deemed incapable or incompetent of adequately developing their children's brains places parents at the center of the policy stage but at the same time demotes and marginalizes them as parents and human beings. This runs the risk of permanent removal from birth families (i.e., rescuing the child) and undermining the possibility of spontaneous relationships of love and care (MacVarish et al., 2015). Similarly, Edwards et al. (2015) argue that in such a discourse, success in life is un-problematically correlated with brain structure and intelligence. And the solution to poverty would then be to make people smarter, so their children can 'think themselves out of their predicament' (p. 184). Edwards et al. (2015) elaborate that within such a discourse poor parents are seen as architects of their children's poverty and deprivation. This point is illustrated in the following excerpt from Our Kids:
Cognitive stimulation by parents is essential for optimal learning. Children who grow up with parents who listen and talk with them frequently develop more advanced language skills than kids whose parents rarely engage them in conversation (as happened with Stephanie, who explained, "We ain't got time for all that talk-about-our-day stuff"). The brain, in short, develops as a social organ, not an isolated computer. (Putnam, 2015, p. 110)

\section{Magic Bullets}

To be fair, Putnam recognizes the limitations of braindevelopment inspired interventions. At the end of the chapter on parenting, he acknowledges that although correlations between parental social class, parenting practices and child outcomes might have been established, most of the studies are not able to prove any causality. Putnam furthermore writes that maternal deprivation (i.e., poor nutrition, inadequate health care, exposure to environmental risks from bad housing) can have powerful long-term effects on children's intellectual and emotional development. In his words: "Even ideal parenting cannot compensate for all the ill effects of poverty on children." (Putnam, 2015, p. 134). However, such remarks almost read as a footnote of the chapter on parenting. The lesson that sport researchers can learn from this is to be sensitive and critical to moralizing approaches and deficiency discourses regarding the inclusion in and through sport of children living in poverty. As mentioned above, research failing to incorporate wider structural dimensions risks legitimating a reductive analysis of complex processes (Kelly, 2011). To rephrase: even ideal coaching cannot compensate for all the ill effects of poverty on children. Sport offers no magic bullets in relation to combatting issues of social exclusion, poverty and inequality. Putnam states that the only 'magical bullet' being able to counter social-class segregation and the dire outcomes for children and societies it brings with it, is the sustained economic revival for low-paid workers. In his final chapter, Putnam (2015) summarizes the key message of his book and the importance of addressing the widening socio-economic gap:

This is not the first time in our national history that widening socio-economic gaps have threatened our economy, our democracy, and our values. The specific responses we have pursued to successfully overcome these challenges and restore opportunity have varied in detail, but underlying them all was a commitment to invest in other people's children. And underlying that commitment was a deeper sense that those kids too, were our kids. (p. 261)

\section{Acknowledgements}

I would like to think Daniel Roe (Swedish School of Sport and Health Sciences) for his valuable feedback on this text. 


\section{Conflict of Interests}

The author declares no conflict of interests.

\section{References}

Eccles, J., \& Gootman, J. (2002). Community programs to promote youth development. Washington, DC: National Academy Press.

Edwards, R., Gillies, V., \& Horsley, N. (2015). Brain science and early years policy: Hopeful ethos or 'cruel optimism'? Critical Social Policy, 35(2), 167-187.

Feinstein, L., Bynner, J., \& Duckworth, K. (2006). Young people's leisure contexts and their relation to adult outcomes. Journal of Youth Studies, 9(3), 305-327.

Kelly, L. (2011). 'Social inclusion' through sports-based interventions? Critical Social Policy, 31(1), 126-150.

Macvarish, J., Lee, E., \& Lowe, P. (2015). Neuroscience and family policy: What becomes of the parent? Critical Social Policy, 0261018315574019.

Putnam, R. (2015). Our kids. The American dream in crisis. New York: Simon \& Schuster.

\section{About the Author}

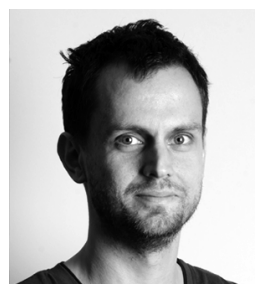

Reinhard Haudenhuyse holds Master's degrees in Physical Education and in Conflict and Development, both from Ghent University. In 2012 he received his PhD in Physical Education and Movement Sciences at the Vrije Universiteit Brussel. He currently works as a part-time professor and post-doctoral researcher at the Sport and Society Research Unit and the Interdisciplinary Research Group Voicing At-Risk Youth at Vrije Universiteit Brussel. 